\title{
A PoÉtica e a RessonÂncia da Loucura em "Aberração", de Bernardo Carvalho
} The Poetics and Resonance of Madness in "Aberração", by Bernardo Carvalho

\author{
Julián Bargueño* \\ Brunilda Reichmann*
}

INTRODUÇÃo

Em Aberração, sua primeira obra, datada de 1993, Bernardo Carvalho já expõe ao leitor os traços marcantes de seu estilo labiríntico e instigante que questionará, muitas vezes implicitamente, os limites entre a identidade e o todo, a loucura e a razão. O conto homônimo, último desta coletânea de onze histórias, todas intensamente entrecortadas pela crescente percepção de realidades alteradas, tem o poder de tornar-se o ápice de tal mecanismo. Ao ser lido na sequência linear da obra completa, manifesta-se como a "conclusão inacabada" de uma proposta que, por sua vez, parece não ter um início palpável: o momento latente em que as raízes com o "real" são perdidas. Isolado de seu contexto, "Aberração" tampouco perde suas propriedades evidentes de "obra-clímax". Suas páginas finais serão suficientemente críveis e incitadoras para que o leitor seja transportado para uma realidade na qual se reconheça como colaborador de criação.

Vários são os fatores que contribuem para o surgimento da noção de "loucura" no conto. Em cada leitura, novos pontos surgem e a fusão entre os fatos e as percepções destes torna-se difusa, levando o leitor a questionar a linha tênue existente entre realidade e imaginação. 


\section{O ENREDO}

O argumento inicial de "Aberração" apoia-se no encontro casual do narrador-personagem com uma foto que o instiga. Após haver passado certo tempo isolado de contatos mais próximos com a sociedade, este narrador já nos apresenta a ideia implícita de uma "desconexão" com o mundo real ou "lógico", criando no leitor, através do trilhar de variados caminhos, a sensação inicial - que irá se desenvolver ao longo do texto - da incapacidade de perceber a diferença e os limites entre loucura e razão.

$\mathrm{O}$ que inicialmente parece ser apenas a atração do personagem por uma foto à venda em um museu, termina por criar uma série de conexões desenfreadas que o instigam a investigar o desaparecimento de sua tia, muitos anos antes. Forma-se, então, uma curiosidade crescente que se transforma em obsessão: o personagem-narrador deixa de lado qualquer outra motivação de existência e parte até o local do acidente, no qual supostamente sua tia morreu: "chegou uma hora em que não dava mais para deixar de ir" ${ }^{\prime}$. Ao pesquisar sobre o fotógrafo que estaria por trás desse mistério, dessa "reconstituição afetiva" feita por imagens que parecem se completar, o narrador acredita estar desvendando fatos que o levariam à solução do desaparecimento de um membro de sua família. Mais tarde, já tomado por um impulso inevitável, o personagem-narrador chega a seu limite e parte para o interior da França, ao acreditar que a solução do mistério esteja lá. $O$ personagem não esconde sua alteração em relação à realidade e à visibilidade do fato pelos que o cercam: "quando me perguntaram o que eu ia fazer lá, disse que estava apenas precisando de umas férias. Quando me perguntaram férias de quê, não respondi, porque não respondo a provocações"2.

\section{A Possibilidade DA Loucura}

Se houve um tempo em que, ao praticamente substituir a lepra e as doenças venéreas em hospitais da Europa, a loucura parecia desenhar sozinha seus próprios limites entre o que poderia ser chamado de sanidade e a falta desta, hoje temos uma percepção inversa. A loucura parece haver-se mesclado com a paisagem habitual e, escondida em meio ao todo, suas linhas divisórias tornam-se difusas e de difícil detecção. Os loucos, na Eu- 
ropa do passado, eram abandonados e despachados em navios para serem jogados à própria sorte, ou talvez nenhuma, pois, como afirma Foucault, "a navegação entrega o homem à incerteza da sorte: nela, cada um é confiado ao seu próprio destino, todo embarque é, potencialmente, o último. É para o outro mundo que parte o louco em sua barca louca; é do outro mundo que ele chega quando desembarca" ${ }^{3}$. O que afirmar, então, sobre um mundo em que, a cada segundo, há milhares de embarques e desembarques, partidas e chegadas, passageiros em trânsito? Em busca de sua tia desaparecida (e de que algo mais?), o narrador de "Aberração" parte constantemente: não só para os lugares específicos que parecem chamá-lo - o local do acidente do avião, Paris e o interior da França - mas também para o desconhecido. Há uma noção de rendição à própria sorte por parte desse detetive que, talvez por não encontrar-se, precisa de algo que o encontre. Nessa entrega pela busca da razão, a partida interior parece ser o início de várias outras que dão sequência a uma sucessão de motivos que se alimentam. Em um mundo no qual não se consegue distinguir o real do imaginário, ou mesmo apontar, entre tantas possibilidades, qual é a verdadeira aberração - e se esta existe -, a escolha por embarcar em uma viagem (física e simbólica) termina por simbolizar uma possível busca de si mesmo. Ao aventurar-se em sua missão, o narrador de "Aberração" escolhe inevitavelmente a possibilidade de nunca chegar, ou talvez não saber distinguir se o primeiro passo é dado em direção à razão ou à loucura, caso esta já não tenha sido o próprio movimento que originou o passo inicial.

Se "o apego a si próprio é o primeiro sinal da loucura" ${ }^{4}$, poderíamos considerar que não apenas o narrador de "Aberração" é reflexo de seu próprio apego ao ampliar sua imagem em uma história imaginada, considerada fruto da razão, motivo de instigante procura de explicação, como este também necessita de todas as confirmações que busca para poder existir. Teríamos, portanto, um personagem que não existiria se sua loucura tampouco existisse: é ela que o torna real. Da mesma forma, ao perceber sua loucura não como tal, mas sim como evidência de um projeto arquitetônico que precisa ser desvendado - pois a noção real de uma loucura já inviabilizaria todo o processo - o narrador-personagem confirma, através deste processo, sua própria existência. Seria, portanto, a loucura o eixo sustentador de um raciocínio lógico necessário para levar o narrador a juntar as peças que, teoricamente, desvendariam o mistério sobre a tia desaparecida. Sem a loucura não haveria nada: fotos com algum sentido, o barco que esconde um suposto assassinato, a uruguaia, o arquiteto e o fotógrafo francês, a tia desaparecida e, no mais 
extremo dos casos, o próprio personagem. Talvez seja sua loucura o que o mantém vivo. Talvez seja isso que faz com que uma história obsessiva exista. Sem a loucura não apenas não existiriam os fatos, mas mais do que tudo, não existiria a pessoa, o personagem, o narrador. O papel do leitor seria de outra natureza caso a loucura não estivesse ali, pois esta viabiliza essa sequência de acontecimentos e fatos que se desenvolvem unidos à ilusão de interdependência, quando na verdade tais fatos pertencem apenas a um mundo idealizado pelo fruto de tal loucura. A loucura pode ser considerada, então, gênese do processo narrativo, do desenvolvimento deste e, em última instância, da possibilidade da existência de uma leitura - qualquer que esta seja - para essa criação desenfreada e aparentemente impulsiva. Apesar de termos a ilusão de um processo criativo descomedido por parte do narrador - afinal, como poderia essa história ser verdade? -, este certamente tem por trás de si o toque de uma loucura específica, notável por disfarçar-se de razão, de lógica, de coerência (a principal entre várias facetas).

Há, portanto, mais do que um simples motivo, uma singela tendência do leitor a sentir, inicialmente, que a tal "aberração" que o título anuncia está ainda sempre por vir, que tardamos em chegar a ela. Na realidade, esta aberração já parece haver-se iniciado antes mesmo da leitura do título. É justamente esse disfarce de razão adquirido pela loucura do narrador que torna sua percepção tão difusa e, por muitas vezes, lenta: lembremos que é possível que a moça da foto seja de fato tia do narrador; o avião do álbum de fotografias da família seja realmente o mesmo do catálogo do fotógrafo francês; que a moça na água esteja verdadeiramente sendo afogada para que a tia do narrador tome seu lugar. A princípio, nada disso é impossível. Tudo faz sentido. E esse sentido, essa coerência, parecem ser o motivo da lentidão em percebermos a loucura: ela toma diversas formas, expressa-se através de diferentes linguagens. Ao mesmo tempo em que poderíamos assimilar a ideia da loucura como "falta" de razão, delírio sem raciocínio, perda do controle, em "Aberração" a loucura toma justamente a forma oposta. Aqui, ela é similar à obsessão, talvez até mesmo ultrapassando-a ao criar uma rede de "hiper-razões", raciocínios aparentemente lógicos e óbvios dentro de um mundo autocriado com suas próprias regras de sentido.

Qual a nossa reação ao ouvirmos uma história que se assemelha a qualquer outra, com argumentos lógicos, causas possíveis e consequências prováveis? Temos a sensação de estar ouvindo um fato aceitável dentro dos parâmetros da razão, do mundo real, da aceitabilidade do real. Como afirma Foucault:

A loucura torna-se uma forma relativa à razão ou, melhor, loucura e razão entram numa relação eternamente reversível que faz com que 
toda loucura tenha sua razão que a julga e controla, e toda razão sua loucura na qual ela encontra sua verdade irrisória. Cada uma é a medida da outra, e nesse movimento de referência recíproca elas se recusam, mas uma fundamenta a outra ${ }^{5}$.

Dentro da narrativa de "Aberração" há, porém, um limite variável que, em algum momento, transforma e revela a loucura por trás da razão ou ainda, a loucura de "que é feita" essa aparente razão. É nesse momento - que certamente irá variar de uma leitura a outra, de um leitor a outro que percebemos um narrador cruzando os limites da razão, do "aceitável" (porém não do lógico, pois essa loucura é alimentada vigorosamente pela coerência racional) e avançando por um terreno assustador em que o leitor começa não só a questionar a sanidade do narrador, mas sua própria lucidez ao entrar em contato com a narrativa e levantar tais questões. Há então uma fusão entre a loucura do narrador e a "loucura" do leitor, que começa a duvidar de si mesmo na mesma proporção em que o narrador está cada vez mais certo de sua história.

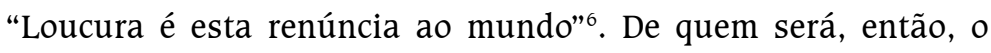
mundo em que vive o narrador de "Aberração"? Ao escolher viver a vida do outro, decifrar enigmas diversos, colocar nas mãos alheias sua própria existência, não estará o narrador renunciando a seu mundo? A escolha de tornar sua existência o ponto de apoio para a resolução de um viver que não é seu, pode ser considerada uma renúncia? E o leitor, ao acompanhar a loucura deste narrador, não está, também, escolhendo viver outra vida? Não estará momentaneamente "enlouquecendo" ao tentar assimilar a possível incoerência à sua frente? Talvez seja pela ilusória sensação de proteção que a lógica nos proporciona que escolhemos "enlouquecer" dentro de limites autoexplicáveis, disfarçados de razão, encobertos pela narrativa. O narrador de "Aberração" inicia esse processo da mesma forma: acreditando em possibilidades que fazem sentido. 0 momento em que a linha tênue é cruzada, porém, é de tão difícil deteç̧ão como a visualização da linha propriamente dita: "A loucura torna-se uma das próprias formas da razão. Aquela integra-se nesta, constituindo seja uma de suas forças secretas, seja um dos momentos de sua manifestação, seja uma forma paradoxal na qual pode tomar consciência de si mesma. De todos modos, a loucura só tem sentido e valor no próprio campo da razão"7. 


\section{O Narrador-Personagem em sua Autopercepção}

A absorção da noção de "loucura" parece ser o ápice subliminar de "Aberração", correndo paralelamente a um enredo que nos confunde ao confundir o narrador em sua função de personagem. Este narrador, porém, apesar de toda sua perturbação, não pretende esconder sua notável lucidez diante da própria incapacidade de evitar algum tipo de "desconexão" entre si mesmo e a realidade, criando novas lógicas e "distorções" da razão. Nessa fusão de acuidade e nebulosidade mental, cria-se um combate entre as duas, fazendo com que a "vitória" passe de um lado a outro temporária e intermitentemente. Existe, então, em tais momentos de colisão, a confirmação seguida e contínua ao longo da obra por parte do narrador em relação ao seu estado alterado. $O$ início do conto pode ser considerado, portanto, como o primeiro "movimento" da lucidez do narrador em confronto com seu estado de "suspensão": "Tudo se embaçou agora. Logo agora que estou aqui, parado, com os braços caídos na frente destes olhares estarrecidos. E isso depois de achar que estava vendo tão claro"8.

Cria-se, a partir desse momento, uma relação de "confidência invisível" entre o narrador e o leitor à medida que o primeiro vai revelando ao segundo suas percepções sobre si mesmo, conseguindo assim capturá-lo para dentro de uma armadilha que o integrará ao conto e possibilitará que as palavras pronunciadas pelo narrador se transformem nas que o próprio leitor poderia pronunciar interiormente: "Estava dentro de uma espécie de surto" ; “[...] um desespero que não estava em lugar nenhum mas estava, ainda assim, por toda parte"10.

Em um diálogo consigo mesmo, o narrador de "Aberração" expõe o leitor à sua constante confirmação de "enlouquecimento". A narrativa não linear do conto é maximizada quando o narrador entra em um processo de "não lembranças" que subvertem a noção de tempo na obra. Através de afirmações que negam sua própria existência, a narrativa se transforma em uma sequência de fatos que se tornam duvidosos pela maneira com que são narrados. Se por um lado o narrador nos conta o que aconteceu, por outro afirma constantemente que não se lembra dos acontecimentos. O leitor é, então, levado a questionar não só a veracidade do que lhe é exposto, mas também a sanidade do personagem que narra o que não consegue recordar:

[...] todas as imagens sumiram agora que estou aqui. [...] Não me lembro dos tios lá em casa nem do telefone que não parava de

CARVALHO, 1993, p. 145.

Ibid., p. 144.

Ibid., p. 161. 
tocar. Não me lembro do grito que tive que ouvir quando perguntei ao meu pai o que estava acontecendo ou de ter ido dormir mais cedo. Não me lembro da minha avó calada num canto, olhando pela janela, nem da histeria de um primo que começou a gritar e chorar sem parar quando ouviu alguém comentar que talvez ela estivesse morta, a tia desaparecida, sem que ninguém jamais tenha sabido como, nem por quê, nem onde. Não me lembro da empregada servindo o café e de uma outra tia derramando tudo na saia e de não conseguir fazer a mão parar de tremer. Ou de todos que chegavam sempre sem nenhuma novidade, nunca, nenhuma novidade, nada. [...] Não me lembro de nada ${ }^{11}$.

Em sua contínua revelação sobre um estado mental em decomposição, o narrador de "Aberração" termina por criar uma paisagem de insegurança e confusão que se mostrará determinante para o impacto psicológico do conto. Ao demonstrar clareza sobre sua condição mental, o narrador termina por "desordenar" a percepção do leitor em relação à loucura. É inevitável questionar a sanidade do personagem que narra: como poderemos chamar de louco aquele que se revela insano, que percebe sua loucura, que a expõe, que a explica, que se mostra tão lúcido dentro da própria falta de razão? Segundo Foucault, "não se pode supor, mesmo através do pensamento, que se é louco, pois a loucura é justamente a condição de impossibilidade do pensamento"12. Dessa forma, cria-se uma constante dúvida sobre o conceito de sanidade e realidade que é apresentada no conto. O leitor é jogado de um lado a outro, tentando encontrar uma possível "verdade" em meio a uma paisagem que mescla concepções contraditórias de loucura, criando assim um panorama de impossibilidades que se apresentam de formas inexplicavelmente concretas.

\section{A SONORIDADE}

Desde suas palavras de abertura até os últimos parágrafos do texto, "Aberração" parece sugar-nos em direção a um "espaço sonoro" próprio. Ao fazer uso de repetições que se formam como mantras em um processo hipnótico particular, seus refrões ecoam por todo o conto, lembrando o leitor não só do conteúdo de suas falas, mas principalmente levando-o a mergulhar em um torpor que o confunde. A sonoridade se torna, assim, um

\footnotetext{
Ibid., p. 150-151.

FOUCAULT, 2008, p. 46.
} 
instrumento poderoso de sedução. Dentre as várias passagens que ressoam, podemos destacar três:

- "Olhares estarrecidos" é repetida 26 vezes;

- "Braços caídos", 17 vezes;

- "Tia desaparecida", 25 vezes.

Nota-se que os trechos escolhidos apresentam expressões impactantes, de surpresa e provocação, agindo de forma a manter o leitor não só em um estado de choque, mas também de curiosidade em relação à trama. Através da repetição desses "refrões", somos impossibilitados de esquecer que algo está errado, que há uma espécie de caos instalado.

Além dessas passagens principais, podemos apontar outras que, apesar de se repetirem com menos frequência, contribuem para a sonoridade particular do conto, agindo como "arranjos musicais semânticos" ao "circular" por todo o texto:

- "Mulher mais bonita do mundo";

- "O pé mais bonito do mundo";

- "O sorriso mais bonito do mundo";

- "Tudo se embaçou agora";

- "Depois de eu achar que estava vendo tão claro";

- "Agora que estou aqui";

- "Todas as imagens sumiram";

- "Devo ter esquecido";

- "Não tenho mais certeza de nada";

- "Não me lembro de nada".

Ao mesclar esses trechos aleatoriamente, "Aberração" termina por "magnetizar" o leitor, em uma somatória de efeitos que se multiplicam e sobrepõem, criando um ambiente onde a perda de direção se confunde com sua própria busca.

\section{O Estranhamento como Ferramenta}

Em seus mais variados e obscuros processos de "enlouquecimento progressivo", "Aberração" obtém um resultado peculiar sobre o leitor: a sensação constante de estranhamento que domina a narrativa. Na passagem em que somos informados da possível morte da tia desaparecida em um acidente de avião, o casal de passageiros que a acompanhava na viagem é exposto pelo narrador de forma claramente distorcida. O narrador, ao voltar 
no tempo e explicar como foi o embarque de sua tia no avião, refere-se ao casal como "os dois mortos", ainda que estes estivessem vivos naquele momento. A narrativa explica, de forma alterada, como foi o encontro da tia e do casal. Quando se refere a ela, o narrador parece estar ciente do tempo e espaço da situação. Ao referir-se ao casal, porém, demonstra uma alteração, descrevendo-os como se já estivessem mortos: “[...] garante ter visto minha tia entrando no avião, colocando a bolsa no banco de trás para logo em seguida embarcar com os outros dois mortos" ${ }^{13}$; "os dois mortos já a esperavam havia algum tempo em frente ao único hangar" ${ }^{14}$; “[...] olhou para os dois mortos e foi caminhando até eles, os cumprimentou e os seguiu até o avião que seria encontrado só no dia seguinte, espatifado entre as árvores" ${ }^{15}$.

Vários são os mecanismos que sugam o leitor para dentro da percepção crescente de loucura que o narrador apresenta. Na primeira "cena" do conto, em que o narrador se encontra em um museu, caminhando solitariamente por entre as pessoas e as obras, pode-se sentir uma estranha "despersonalização" da sexualidade do personagem. Com um impulso sexual dirigido a objetos, ao vazio e ao abstrato, é clara a noção de que o narrador-personagem se encontra em um estado de pouca interação com seus semelhantes. Sua relação não é com pessoas, mas com o espaço físico que o cerca:

Desde a primeira vez tinha sido assim. Ao contrário dos outros, aquele museu me excitava - no sentido menos figurado da palavra. Talvez fossem as paredes brancas e os quadros, mas eram como em toda parte. Era um desvario no meio de toda aquela calma: de sala em sala, de repente começava e era como se eu tivesse perdido todos os limites, todos os critérios. Nunca me preocupei realmente com aquelas ereções; era um prazer ficar assim na frente dos quadros [...] e de sala em sala eu ia com a mão cobrindo a calça, de sala em sala, demente, a que ponto eu chegava depois de um mês sozinho. [...] Quando já não podia mais de dor, com o pau espremido entre o jeans e as coxas, um vexame, saindo pelo lado da cueca, entrei na lojinha de souvenirs, querendo esquecer tudo, os quadros e as paredes, e, girando um dos suportes de cartões-postais, acabei batendo com os olhos num que reconheci imediatamente $[\ldots]^{16}$.

Ao acompanharmos o narrador em sua caminhada desenfreada, somos testemunhas do momento em que este parece se "desprender" da realidade, alterando assim a aparente lucidez com que vinha descrevendo

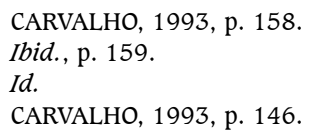


sua própria loucura até então. Inicia-se, nesse instante, uma narrativa de "perda de controle", de livre associação:

Penso no que nem mesmo eles pensam mais, porque devem estar realmente muito longe, agora que têm apenas olhares estarrecidos para me olhar, não mais capazes de cogitar o que foi afinal, o que levou um a adorar os olhos do outro e este ou esta o cabelo do terceiro ou terceira, estarrecidos que estão, e eu com os braços caídos só penso neles e no que não pensam mais, talvez nem saibam mais que viveram. [...] nem cogitam ter havido uma razão ou mesmo uma irrazão, uma coincidência, não pensam, porque esteve sempre longe demais, porque o segundo dia já era uma eternidade e o terceiro um motivo para as recordações dos anteriores e os risos, as gargalhadas sobre o passado de dois dias, desde que se conheceram já era para sempre e havia muito tempo ${ }^{17}$.

Ao disparar por um caminho que já se torna inevitável, a narrativa chega então a seu clímax, revelando de forma veemente o estado mental do personagem:

[...] eu não reconheço mais nem ela nem os outros dois, ela não se parece mais com a mulher mais bonita do mundo nem com aquela das fotografias, nem eles, tudo se embaçou com esses três olhando estarrecidos para mim, espantados como se eu fosse uma assombração ou um bandido, um assaltante, porque sabem que descobri tudo, que agora está tudo acabado e vão fingir que não, que não sabem de nada, que eu sou só um assaltante, é lógico, e um deles até já correu para dentro de casa, para na certa pegar a espingarda, e me matar, mas mesmo assim eu continuo avançando na direção deles e berro já no meio da estrada, com todas as minhas forças, porque apesar de tudo ainda guardo este amor no meu peito: Titia!, e toda a minha história desaparece num instante $^{18}$.

Ao pronunciar as últimas palavras, o narrador termina por concretizar o que vinha se apresentando ao longo do conto. Em uma afirmação dúbia, que não resolve ou explica a realidade, maximiza a sensação de 
estranhamento já instalada na narrativa. Ao "desaparecer a história”, o narrador recuperou sua consciência ou perdeu-a definitivamente? Enlouqueceu ou recobrou a razão? O estado de suspensão criado por essas "reticências mentais" mantém-se de forma a valorizar a percepção de que não há razão ou loucura isoladamente, mas sim uma existindo em contraste e fusão com a outra: "Onde, pois, situá-la (a loucura) senão na própria razão, como uma de suas formas e talvez um de seus recursos? Sem dúvida, entre formas de razão e formas de loucura, grandes são as semelhanças" ${ }^{19}$.

\section{Considerações Finais}

Em "Aberração", são vários os questionamentos que tomam conta do leitor. De quem são os olhares estarrecidos? Por que o narrador tem os braços caídos? Como pode o narrador relatar tudo aquilo de que diz não se lembrar? A tia desaparecida morreu, foi assassinada ou é tudo um grande plano para escondê-la? Existe um grande mistério ou fomos testemunhas de um fato cotidiano?

Sob um olhar mais meticuloso, porém, detecta-se que tais perguntas terminam por colocar-se em segundo plano, pois outros "mistérios" saltam à frente da trama que se desenvolve. Questões sobre os limites entre o familiar e o secreto, a realidade e a ilusão e, em última análise, entre a razão e a loucura passam a dominar o leitor que, ao não encontrar solução para seus conflitos, passa a pôr em dúvida não só a legitimidade dos fatos como sua própria percepção da realidade retratada no conto. Ao visualizar-se submerso em dúvidas, o leitor torna-se testemunha das contradições criadas pela suposta "razão" do narrador, que ora surge em meio a uma lucidez questionável, ora em meio a uma insanidade coerente: "O abismo da loucura em que estão mergulhados os homens é tal que a aparência de verdade que nele se encontra é simultaneamente sua rigorosa contradição" ${ }^{20}$.

\section{RESUMO}

Este trabalho tem como objetivo analisar, remetendo a Michel Foucault e suas ideias sobre a loucura, de que forma é criado e desenvolvido na narrativa o mundo paradoxal do narrador de 
"Aberração", conto do livro homônimo de Bernardo Carvalho. Neste universo em que o leitor é inserido, características consideradas extremas como a razão e a loucura, o bom senso e a perda de referências passam a ocupar o mesmo espaço, dividindo as mesmas responsabilidades e funções, em um contínuo diálogo de contradições que se complementam. Ao mergulhar em um mundo em que limites desaparecem, o leitor é forçado a desvendar seu próprio mistério em uma narrativa que une devaneios, sexualidade e hipnotismo sonoro ao construir um discurso instável e provocante.

Palavras-chave: Narrativa ficcional; loucura; razão.

\begin{abstract}
This paper aims at analyzing, by using some ideas about madness by Michel Foucault, the ways in which the paradoxical world of the narrator of "Aberração", a short story from the homonymous book by Bernardo Carvalho, is created and developed. In this universe, in which the reader is inserted, characteristics, like reason and madness, common sense and loss of reference, begin to occupy the same space, dividing the same responsibilities and functions, in a continuous dialog of complementary contradictions. On emerging into a world in which limits disappear, readers are forced to unveil their own mystery in a narrative that combines illusion, sexuality and resonant hypnotism, while building an unstable yet provocative discourse.
\end{abstract}

Keywords: Fictional narrative; madness; reason.

\title{
REFERÊNCIAS
}

ALMEIDA, Claudia. Encontros desencontrados. Disponível em: < http://www.c-e-m.org/reflexoes/019/4.htm > . Acesso em: 19/09/2009.

AUGUSTO, Daniel. Um qüiproquó metódico: os romances de Bernardo Carvalho. Disponível em: <http://pphp.uol.com.br/tropico/html/textos/2374,1.shl>. Acesso em: 19/09/2009.

CARVALHO, Bernardo. Aberração. São Paulo: Companhia das Letras, 1993.

. Exclusivo e fictício: a desconstrução da paranóia. 2004. Disponível em: <http://www1. folha.uol.com.br/fsp/mais/fs2504200404.htm >. Acesso em: 15/09/2009.

. Rascunho: paiol literário. 2007. Disponível em: <http://rascunho.rpc.com.br/ index.php? ras $=$ secao.php\&modelo $=2 \&$ secao $=45 \&$ lista $=0 \&$ subsecao $=0 \&$ ordem $=1504>$. Acesso em: 15/09/2009.

FOUCAULT, Michel. História da loucura. Tradução: José Teixeira Coelho Neto. São Paulo: Perspectiva, 2008. 
JATOBÁ, Vinícius. A carpintaria de Bernardo Carvalho. Disponível em: <http://portalliteral. terra.com.br/Literal/calandra.nsf/O/C6297E164A4F80B9032572CF0034A798?OpenDocument $\&$ pub $=$ T\&proj $=$ Literal\&sec $=$ Ponto + de + vista $>$. Acesso em: 15/09/2009.

REZENDE, Beatriz. Beatriz Resende entrevista Bernardo Carvalho. Disponível em: < http://www. pacc.ufrj.br/z/ano3/02/bernardocarvalho.htm>. Acesso em: 15/09/2009.

VASQUES DA CUNHA, Martim. Bernardo Carvalho e a arte da fuga. Disponível em: <http:// www.digestivocultural.com/colunistas/coluna.asp?codigo=1315>. Acesso em: 15/09/2009.

VIEIRA, Yara. Diante do espelho: refração e iluminação em Bernardo Carvalho. Disponível em: <http://www.accessmylibrary.com/coms2/summary_0286-13888020_ITM >. Acesso em: 15/09/2009.

Submetido em: 31/10/2009

Aceito em: 16/01/2010 